\title{
КУЛЬТУРНАЯ ПОЛИТИКА
}

УдК 304.4(470+571) + 304.4(510)

ББК 71.41(2Рос) + 71.41(5Кит)

\section{Е.А. КАРЦЕВА}

\section{COBPEMEHHOE ИСКУССТВО В КОНТЕКСТЕ ГОСУДАРСТВЕННОЙ КУЛЬТУРНОЙ ПОЛИТИКИ. ОПЫТ КИТАЯ И РОССИИ}

\author{
Екатерина Александровна Карцева, \\ Международный университет в Москве, \\ кафедра прикладной культурологии и социокультурного \\ менеджмента, \\ старший преподаватель; \\ портал о культуре и искусстве Artandyou.ru, \\ главный редактор \\ Ленинградский просп., д. 17, Москва, 125040, Россия \\ кандидат культурологии \\ E-mail: katyakartseva@gmail.com
}

Реферат. В последнее время в стране наблюдается интенсификация государственных управленческих u законотворческих инициатив в сфере культуры. Происходит попытка трансформации прежнего узковедомственного подхода к культуре в единую стратегию работы государственного аппарата. Культура возводится в ранг национальных приоритетов. Государство намерено выступать одним из ее основных стратегических инвесторов и идеологов. В принятой «Стратегии государственной культурной политики на период до 2030 года» под культурой понимается система традиционных для России изенностей, сохранение и поддержка которых выступает гарантом национальной безопасности, «цивилизационной самобытности» страны перед вызовами внешнего мира. Активное внимание государства к сфере культуры можно трактовать как возвращение патерналистского подхода. Одной из наиболее проблемных в этом смысле сфер становится современное искусство, которое во многом достаточно маргинально и может не совпадать с приоритетными для государ- ства культурными смыслами и формами. Представляется актуальным сравнить политику в области современного искусства в России и Китае, где культура как основа национальной идентичности также возведена в ранг государственных приоритетов.

Ключевые слова: современное искусство, культурная политика, арт-рынок, Россия, Китай.

Для цитирования: Карцева Е.А. Современное искусство в контексте государственной культурной политики. Опыт Китая и России // Обсерватория культуры. 2017. Т. 14, № 2. С. 157-166.

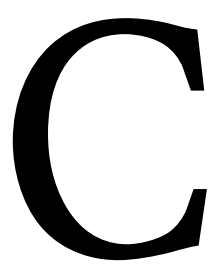
уществует дифференциация на Западе на Modern Art (1870-1970 гг.) и Contemporary Art (с 1970-х гг. по наше время). В русском языке оба этих определения звучат как современное искусство. Однако в российском языке есть также понятие «актуальное искусство», часто выступающее синонимом «современного искусства». Возникают терминологические трудности, какое искусство является современным? В данной статье под современным искусством понимаются произведения художников, чья карьера (или пик ее развития) пришлись на время после 1991 г., после перехода России к свободному рынку. В силу взаимного пересечения различных художественных практик также может возникать неоднозначность трактовок «художественности», что является искусством, а что нет? Сегодня творческая актуализация художников может принимать различные формы, выйдя далеко за рамки традиционной живописи или скульптуры. Инсталляции, искусство новых медиа, перформан- 
сы, реди-мейды, хэппенинги и другие художественные новации были характерны уже для искусства модернизма. В попытке разобраться в терминологии уместно привести определение философа и теоретика Бориса Гройса: «Modern art работало на уровне индивидуальной формы. Contemporary art работает на уровне контекста, формата, фона или новой теоретической интерпретации. Поэтому contemporary art не столько индивидуальная продукция, сколько манифестация индивидуального решения, включить или исключить вещи и образы, анонимно циркулирующие в нашем мире, - дать им новый контекст или лишить их его: частный выбор, который одновременно публично доступен и через это манифестирован, представлен, ясно определен» [1]. Ближайшее значение к «contemporary art» в русском языке - это «актуальное искусство». При этом ничто не мешает актуальным художникам мастерски работать и в традиционных техниках, в том числе живописи, но отличием от традиционалистов будет то, что их художественной опорой является не сам холст, а пространство и контекст, в которые картина включена: «То, что отличает современное искусство от искусства прежних времен, - это то обстоятельство, что оригинальность искусства устанавливается не посредством его собственной формы, но через его включение в определенный контекст, в некую инсталляцию, через его топологическую фиксацию» [1]. Именно такое «актуальное» искусство востребовано международной и российской художественной элитой - ведущими музеями, биеннале, критикой, теоретиками, кураторами и т. д. Но ожидания зрителя, имеющего традиционное восприятие искусства как искусства изящного (Fine art), зачастую порождают конфликт с увиденным. Чиновники в этом смысле выступают также в роли широкой публики, которая не всегда в состоянии адекватно прочитывать художественные смыслы. В их понимании искусство - это картина или скульптура, выполненные мастерски и вызывающие эстетическое наслаждение. Но современное искусство - другое, оно зачастую ищет в окружающем мире не только гармонию, но, в первую очередь, различные противоречия, конфликты. Как следствие - возросшая политизация искусства, что в условиях патерналистского подхода определяет особую напряженность в отношениях власти и искусства.

\section{ОТНОШЕНИЕ ГОСУДАРСТВА К НЕОФИЦИАЛЬНОМУ ИСКУССТВУ В КИТАЕ}

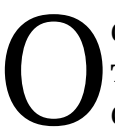

сновным художественным методом в Китайской Народной Республике был выбран социалистический реализм, который хоть и имел национальные особенности, по части идео- логии полностью копировал советский вариант. Станковая живопись маслом в отличие от традиционной Гохуа (термин для обозначения техники и стиля традиционной китайской живописи, в которой используются тушь и водяные краски на шелке и бумаге) не являлась привычной художественной формой для китайского народа и полностью перенята у советских живописцев. Была заимствована и система государственного патроната искусства. Помимо официального искусства в Китае, как и в СССР, развивалось искусство подпольное. Одним из первых его проявлений в конце 1970-х стало течение, получившее название «Искусство раненых», обличавшее насилие, с которым насаждалась культурная революция. Повсеместно неофициальное искусство распространилось в Китае к середине 1980-х гг. и получило название «Движение 85». Если в СССР периодом расцвета неофициального искусства считаются 1960-1970-е гг. и московский концептуализм, то китайское «Движение 85» склонялось к цинической оценке политических событий, будучи ближе к нашему соцарту. Целью этого искусства были социальные и политические перемены: «Это движение не было ради того, чтобы создать новую форму или стиль в искусстве, скорее заботой художников было стать частью социальных реформ», - говорит профессор Питтсбургского университета Гао Минглу [2].

События на площади Тяньаньмэнь в 1989 г. не осуществили перестройку, как это произошло в СССР, но вынудили Китай взять курс на демократические реформы и либерализацию экономики. Коммунистическая партия Китая (КПК) понимает необходимость всесторонних и глубоких преобразований для модернизации социалистической системы. Коммунизм более не представлялся достаточно эффективным в качестве модели национального самоопределения. Начинается поиск новых моделей самоопределения китайской нации, одной из которых становится культура. Проводятся реформы культурной системы. Сокращается разрыв между культурным наследием и современностью, заданный эпохой Мао Цзедуна. Возрождается традиционное искусство и культурные традиции, уничтожавшиеся в период культурной революции. В том числе Гохуа начинает существовать наравне с соцреализмом. Частично переводятся на самоокупаемость и коммерциализацию культурные организации, формируются понятия рынка культуры и его инфраструктура.

В среде неофициального искусства наибольшее развитие получает «цинический реализм», высмеивающий официальный социалистический реализм и политику партии. Это искусство по-прежнему под запретом. Выставка китайского авангарда в 1989 г. была разогнана. Но подпольные художники, как в свое время и советские нонконформисты, стано- 
вятся востребованы западной прессой и коллекционерами, которые считают, что это и есть настоящее лицо современного Китая. КПК достаточно быстро понимает, что важно не только национальное традиционное искусство, которое отражало бы исконные китайские ценности в противовес западным, но и современное искусство, способное доносить эти ценности понятным Западу языком и встраивать Китай в современные контексты. Нонконформизм получает право на существование. С 1996 г. ведет свою историю Шанхайская биеннале, посвященная современному концептуальному искусству. В 1999 и 2001 г. легендарный куратор Х. Зееман приглашает к участию в Венецианской биеннале несколько десятков неизвестных Западу китайских художников. Китайское искусство обретает мировую популярность.

Китай, осуществивший трансформацию в сторону развитой рыночной экономики, также быстро меняется по отношению к когда-то нонконформистскому искусству, оказавшемуся под пристальным вниманием Запада. Государственная цензура становится менее авторитарна, правительство партии устремляет свой взгляд на то, чтобы продвигать китайский продукт, который может приносить деньги. Экономические перемены в китайском обществе, которому открыли путь к частному предпринимательству, также скоро сказываются и на китайском неофициальном искусстве. Цинический реализм, пройдя небольшой инкубационный период, уходит от критики государственного строя к темам массовой культуры и потребительства. Художники обращаются к вопросам личного обогащения, увеличивающегося разрыва между богатыми и бедными, конкуренции. Происходит коллизия между капиталистическим и социалистическим. Зародившийся как нонконформистское искусство, цинический реализм становится в одну линию с политикой партии, популяризируя Китай на международной арене.

\section{РОССИЙСКОЕ ИСКУССТВО В УСЛОВИЯХ СВОБОДНОГО PЫHKA}

$\Pi$ осле распада Советского союза в 1990-е гг. российское искусство становится абсолютно свободным от какой-либо цензуры. Государству по большому счету до искусства нет никакого дела. Однако успешно начавшийся в середине 1980-х гг. бум советского и русского искусства, апофеозом которого стали торги Sotheby's 1988 г., долго не продлился. Завершающим этапом востребованности российских художественных ценностей на мировой арене стало вручение Золотого льва на Венецианской биеннале в 1993 г. И. Кабакову за то- тальную инсталляцию «Красный павильон». Артсообщество пытается формировать инфраструктуру арт-рынка, в том числе для того, чтобы формулировать ценность русского искусства на Западе. В начале 1990-х гг. в стране нет ни музеев современного искусства, ни фондов, а только несколько галерейных пространств, объединивших вокруг себя художников. Исключение составляют отдел новейших течений Государственного Русского музея (с 1991 г.) и созданный в 1994 г. Государственный центр современного искусства (ГЦСИ). По назначению Министерства культуры РФ с 1995 г. ГЦСИ отвечает за участие России на Биеннале в Венеции, характеризующееся в 1990-е гг. регулярной нехваткой средств. Творческие критерии отбора проектов смешиваются с финансовыми. На биеннале отправлялись те художники и проекты, за плечами которых была спонсорская поддержка. Тем не менее к концу 1990-х гг. русские современные художники имеют на мировом арт-рынке совокупно намного больший вес, чем китайские. С точки зрения основных тем ключевые арт-фигуры 1990-х гг., будь то О. Кулик, А. Виноградов, В. Дубосарский, С. Файбисович, В. Комар и А. Меламид, И. Кабаков, эксплуатируют в той или иной форме тему национального в искусстве. Свою миссию они видят в повышении интереса к искусству в обществе, привлечении внимания к современным русским художникам, аккумулировании информации о российском арт-рынке и его основных игроках.

\section{БУМ КИТАЙСКОГО СОВРЕМЕННОГО ИСКУССТВА 2000-2010-х ГОДОВ}

$\mathrm{y}$ глубление реформы культурной системы в Китае происходит с 2003 года. Разрешен допуск частного и иностранного капитала в сферу культуры. Поставлена задача по активизации освоения международного рынка и продвижения китайской культуры во внешний мир [3]. Культурная политика в Китае модифицируется с учетом рыночных условий существования искусства, а сама культура становится основой государственной политики, движущим фактором модернизации. Сфера культуры используется Китаем для ответа на вызовы западной картины мира. КПК вкладывает большие ресурсы в развитие национального искусства и его включенности в мировые процессы. В 2010 г. высший законодательный орган страны - Всекитайское собрание народных представителей - принял пятилетний план, одной из целей которого было увеличение количества музеев до 3,5 тысяч [4]. Культура в этом документе определяется не только как «дух и душа нации», 
но также как стратегическая отрасль и мощный ресурс для развития страны. Уже к концу 2013 г. количество музеев составило 4 тысячи [5]. К строительству привлекаются известные архитекторы. Музеи становятся одним из инструментов территориального брендинга. Многие возводятся частными строительными компаниями, преследующими свои интересы, например становясь градообразующим элементом при сооружении района или города. Китай активно развивается, стимулируя свою экономику. Как возводятся пустующие города, так и музеи необходимо чем-то наполнять, нужны художники и их произведения. Существует риск, что произведений искусства для заполнения музеев может не хватить, и часть их будет перефункционирована [5]. Аналогичным образом строятся мастерские для тысяч художников, художественные деревни. Правительство открывает художественные вузы, осуществляет государственные заказы на живопись. Работают программы обмена с российскими художественными вузами, в которых вторыми по численности после россиян являются китайские студенты.

Другим важным направлением 11-й пятилетки стала Пекинская биеннале современного искусства, проходящая с 2003 года. С 2005 г. у Китая появился собственный павильон на Венецианской биеннале (у России он с 1913 г.). Государственная политика в сфере поддержки современного искусства происходит как путем прямых директив, финансирования и закупок КПК, так и прямым и косвенным стимулированием частных китайских и иностранных инвестиций.

Китай, совершивший экономическое чудо, продемонстрировал его и в сфере современного искусства, в 2010 г. по количеству продаж работ современных художников обойдя Великобританию, а в 2011 г. и США, став мировым лидером на артрынке. Впервые миллионная аукционная продажа за работу китайского художника была достигнута в 2006 г., через год количество семизначных продаж увеличилось с девяти до 76 в 2007 году [6, с. 250]. Ведущие иностранные галереи стремятся представлять китайский авангард, аукционные дома открывать свои филиалы в Китае. В России, например, торги западных аукционных домов не проводятся вообще. Современные китайские художники по уровню цен, за них отдаваемых, опережают американских и западноевропейских, но почти все сделки осуществляются на азиатских торгах. Это говорит о том, что продвижение художников спровоцировано экономическими показателями, и национальная идентичность играет в Китае большую роль. Именно китайские покупатели обусловили рост цен на китайское искусство. Здесь существенное отличие от российских коллекционеров, которые предпочитают инвестировать в западных художников.

Китайское чудо в области арт-рынка спровоцировано экономическим ростом самого Китая и другими факторами, такими как:

• ограничения на покупку иностранных автомобилей, запрет спекуляций с недвижимостью в результате чего национальное искусство - альтернативная форма инвестирования;

- строгое, вплоть до смертной казни, наказание за денежные взятки, которое до недавнего времени обходилось дарением дорогих подарков, в том числе произведений искусства;

• приверженность китайцев коллекционировать то, что представляет ценность для Китая;

- распространенная практика частных музеев, в которых китайцы демонстрируют свои коллекции и т. д.

Несмотря на то что Мао Цзедун сменился на картинах китайских художников с вождя нации на персонажа из комикса, это не сильно заботит правительство Китая, так как современное китайское искусство приносит большие деньги в ВВП страны.

\section{МЕСТО СОВРЕМЕННОГО ИСКУССТВА В РОССИЙСКОЙ КУЛЬТУРНОЙ ПОЛИТИКЕ: 2000-е гг. - НАШИ ДНИ}

$\mathrm{M}$ В 1999 г. открывается первый государственный музей искусства XX-XXI вв. - Московский музей современного искусства, в 2001 г.- отдел новейших течений Государственной Третьяковской галереи, в 2007 г. стартует проект «Эрмитаж 20/21». С 2003 г. - Московская биеннале современного искусства. В 2004 г. ГЦСИ получает новое здание на Зоологической улице, с 2005 г. проводит конкурс на соискание государственной премии в области современного искусства «Инновация», к 2015 г. ГЦСИ представлен в семи регионах России. В 2014 г. Государственный Эрмитаж принимает европейскую арт-биеннале «Манифесту 10».

Помимо Московской биеннале при поддержке Министерства культуры РФ начинают проводиться международные выставки молодого искусства YoungArt, уличного искусства «Артмосфера» (в Москве), Уральская индустриальная биеннале (Екатеринбург), Ширяевская биеннале (Нижний Новгород) и другие фестивали и биеннале по всей стране. К своему 100-летию в 2013 г. на общие со спонсорскими средства реставрируется Павильон России в Венеции. Увеличивается его финансирование. В 2011 г. - 10 млн руб. против предыдущих трех, в 2013 г. - уже 24 млн рублей [7]. В 2011 г. 
А.А. Авдеев, первый за историю новой России министр культуры, посещает Биеннале в Венеции. При его управлении объем господдержки культуры увеличивается на 25\% [8], начинается обновление Государственного музея изобразительных искусств им. А.С. Пушкина, проводятся годы перекрестных культурных обменов: Россия-Франция (2010), Россия-Испания и Россия-Италия (2011), Россия-Германия (2012-2013), в рамках которых проходят крупные выставки русского искусства. Рынок современного искусства в стране развивается. На сегодняшний день несколько тысяч человек считают себя художниками, но в международном масштабе востребована малая часть, в стране не хватает художественных учреждений, нет института коллекционеров [9].

С 2013 г. происходит интенсификация государственных управленческих и законотворческих инициатив в сфере культуры. В 2014 г. утверждаются «Основы государственной культурной политики», а в феврале 2016 г.- «Стратегия государственной культурной политики на период до 2030 года», ведется работа над новой редакцией закона о культуре. Изучение этих программ позволяет провести многочисленные параллели со стратегией китайской культурной политики, где еще в 2007 г. на XVII съезде КПК были выдвинуты цели:

- создавать систему стержневых социалистических ценностей, увеличивать притягательные и цементирующие силы социалистической идеологии;

- формировать гармоничную культуру, воспитывать цивилизованные нравы;

- широко распространять национальную культуру, строить общий духовный очаг китайской нации;

- продвигать новаторство в культуре, усиливать жизненную силу развития культуры [10].

Как и в культурной политике Китая, направленной на противостояние западной модели ценностей, в стратегии российской государственной культурной политики «К угрозам национальной безопасности в области культуры отнесены размывание традиционных российских духовно-нравственных ценностей и ослабление единства многонационального народа Российской Федерации» [11], а приоритетными направлениями называются среди прочего:

- усиление и расширение влияния российской культуры в иностранных государствах;

- сохранение единого культурного пространства как фактора национальной безопасности и территориальной целостности России;

- повышение социального статуса семьи как общественного института, обеспечивающего воспитание и передачу от поколения к поколению традиционных для российской цивилизации ценностей и норм;

- сохранение культурного наследия и создание условий для развития культуры;
- формирование новой модели культурной политики [11].

Для государства культура понимается как носитель определенной, присущей исключительно России системы ценностей. Регулярно президент поднимает вопросы о национальной идее, о дефиците «духовных скреп». Культура объявлена национальным приоритетом. Как и в Китайское программе, одной из приоритетных задач становится увеличение числа музеев: «За последние два года в регионах открыты 36 новых и 65 реконструированных музеев, среди которых целый комплекс музеев Эрмитажа в Санкт-Петербурге; сдвинулись с мертвой точки многолетние, стоявшие стройки Третьяковской галереи и Пушкинского музея в Москве, а также заложен камень в основание Государственного центра современного искусства в столице. На четверть увеличилось количество выставок» [12].

Особое внимание уделяется развитию чувства патриотизма и национальной гордости: «Знаковыми, зачастую уникальными по масштабу стали выставки, посвященные юбилейным событиям: 100-летию Первой мировой войны, 700-летию Cергия Радонежского, 200-летию М.Ю. Лермонтова. Рекордная посещаемость отмечена на интерактивной выставке “Романовы”. В Москве, Санкт-Петербурге, Сибири и в Крыму ее посетило более миллиона человек. Выставку “Рюриковичи" только в Москве за три недели посетили 250 тыс. человек» [12]. Исследователи отмечают, что подобное обилие управленческих инициатив, направленных на сферу культуры, интенсифицированное внимание к деятельности культурных организаций можно расценивать, как возвращение патерналистского подхода к культуре, через которую государство собирается формировать новые смыслы [13].

Пытаясь избежать ошибок СССР, в том числе по ослабеванию «мягкой силы» государства, в Китае полагают, что «с точки зрения внутренней политики, строительство “мягкой силы” Китая благоприятствует усилению национальной мощи, поднятию национального духа, укреплению чувства идентичности народа всей страны, сохранению и развитию лучшей традиционной китайской культуры, а также достижению полного единства Китая» [10]. Спустя какое-то время и в России вопрос «мягкой силы» государства и национального единства ставится на повестку дня. Тем не менее, в ситуации, когда государство принимает на себя культуртрегерские инициативы, актуальное искусство оказывается одной из наиболее проблемных сфер.

Позиция государства относительно актуального искусства неоднозначна. Чиновники берутся судить «художественность» или ее отсутствие на основании личных непрофессиональных мнений, в то время как зачастую отделять искусство от не искусства под силу только представителям экспертного 
сообщества. Министр культуры РФ А.С. Соколов (2004-2008) запомнился тем, что отозвался о работе «Эра Милосердия» группы «Синие носы» словами «Это искусство позорит Россию» [14] и запретил ее к вывозу на выставку «Соц-Арт» в парижском Maison Rouge. Министр культуры РФ В.Р. Мединский был более заметен на выставках современного искусства, чем предыдущие два министра, но отзывался о нем негативно. На заседании оргкомитета по проведению Года культуры в России он отметил: «Почему под современным искусством мы понимаем исключительно что-то непонятно кубическое, корявое, вплоть до груды кирпича, которую представляет собой инсталляция, финансируемая из госбюджета» [15]. Под грудой кирпича подразумевалась инсталляция китайской художницы Инь Сючжень «Температура», символизировавшая как раз строительство в Китае пустующих городов с целью стимуляции экономики и насаждения нового образа жизни.

Несмотря на впервые за многие годы приоритетное внимание к культуре в статье бюджетных расходов для сферы искусства - уменьшение господдержки. В 2014 г. Министерство культуры РФ ликвидирует отдел изобразительного искусства, ориентированный на современное искусство, объединив его с отделом народного творчества, что приравнялось к полному прекращению закупок современного искусства в России. Московская биеннале в 2015 г. получает наименьшее финансирование за все годы своего существования. В мае 2016 г. ГЦСИ становится подразделением Государственного музейно-выставочного центра «РОСИЗО». Центр, скорее всего, лишится выставочного зала на Зоологической улице. В ноябре 2016 г. увольняются руководители основных подразделений ГЦСИ, в том числе худрук Л. Бажанов, руководитель отдела художественных программ И. Горлова, прокомментировавшие уход несогласием с условиями работы, возникшими при реорганизации: «...опыт последних четырех месяцев показал, что мы теперь не можем отвечать за взятые по долгу службы обязательства. Теперь я “общаюсь” с неизвестными мне людьми без лиц, которые сидят где-то далеко и отвечают в системе электронных согласований, редко вникая в суть проекта», - поясняет свою позицию И. Горлова. Л. Бажанов и вовсе говорит о цензуре [16]. Государственное финансирование Павильона России в Венеции в 2017 г. снижается до 7 млн рублей [17].

Наблюдение за российской информационной повесткой позволяет предположить, что ситуация с современным искусством в России неоднозначна, так как не совсем понятно, как оно встраивается в новую стратегию государственной культурной политики. Вопросы с цензурой в профессиональном сообществе стали подниматься разительно чаще и не только в том, что касается современно- го изобразительного искусства, но также и в других видах творческой деятельности. В октябре 2016 г. директор Российского государственного театра «Сaтирикон» им. А. Райкина К. Райкин выступил с критикой попыток государства бороться за «нравственность в искусстве»: «Вот эти группки оскорбленных якобы людей, которые закрывают спектакли, закрывают выставки, нагло очень себя ведут, к которым как-то очень странно власть нейтральна - дистанцируется. Мне кажется, что это безобразные посягательства на свободу творчества, на запрет цензуры. <...> Не надо делать вид, что власть - это единственный носитель нравственности и морали» [18]. Парировал К. Райкину пресс-секретарь Президента РФ Д. Песков, призвавший не путать цензуру с госзаказом, когда государство выделяет финансирование, то оно вправе определять и тему [19].

В России цензура запрещена Конституцией РФ, и государственные лица подчеркивают, что она недопустима, но параллель с Китаем по части контроля государства за производством художественных смыслов провести все же можно. Во-первых, наличие в обоих странах политического искусства ставшие известными на весь мир китайский художник-диссидент Ай Вэйвэй, российские художникиакционисты The Pussy Riot, П. Павленский. Когда после своего ареста в 2011 году Ай Вэйвэй был назван самым влиятельным человеком в мире искусства по версии авторитетного издания The ArtReview, представители МИД Китая выступили с обращением, что «в Китае есть другие не менее достойные внимания художники» [20]. Художественная реальность художников-провокаторов возникает на почве конфронтации с властью. Резонансным в современной российской истории было и уголовное дело, возбужденное к организаторам выставки «Осторожно, религия!» в Музее и общественном центре им. А. Сахарова в 2005 году. Тогда суд признал виновными директора и сотрудницу центра в разжигании национальной и религиозной вражды. В сложившейся ситуации сами художественные институции или кураторы время от времени могут подвергать цензуре художников и их произведения с целью избежать возможной реакции со стороны властей. Например, закрытие выставки фотографии Д. Стерджеса в Центре фотографии им. братьев Люмьер в октябре 2016 г. в Москве после обращения омбудсмена по правам детей Е. Мизулиной в прокуратуру с просьбой проверить произведения на наличие в них детской порнографии. Центр, подчеркивая, что обнаженных несовершеннолетних на выставке нет, все же ее закрыл, после того как один из экспонатов был облит мочой, а вход в галерею заблокировали представители общества «Офицеры России». В ноябре 2016 г. скандал разразился также вокруг выставки Я. Фабра в Государственном Эрмитаже, на которой были представлены чучела жи- 
вотных. В этот раз в ведомстве разъяснили, что для открытия «скандальной» экспозиции петербургский музей не обязан получать разрешения из Министерства [21].

Налицо трудности, с которыми сталкивается российская власть при необходимости смыслового наполнения понятия «современное, актуальное искусство» и выработки стратегии его развития в условиях новой культурной политики. В связи с переходом от «узковедомственного подхода к культуре» в единую стратегию государственного аппарата чиновники в большей степени полагают уместным высказываться насчет сферы искусства. В 2015 г. создается «Фонд развития современного искусства», задачей которого является «организация более тонких коммуникаций с особым сообществом, объединившимся вокруг современного искусства». Фонду содействует Управление Президента РФ по общественным проектам, возглавляет его бывший заместитель министра культуры РФ, председатель президиума Фонда И.И. Демидов, один из создателей «Молодой гвардии "Единой России”», возглавлявший идеологическое управление политического департамента партии.

Пока деятельность фонда не особенно ясна. Теоретик искусства А. Ерофеев характеризует взаимоотношения российской власти и искусства, как перманентный конфликт, застывший в острой фазе, ближе всего к «холодной войне» [22]. В декабре 2016 г. РОСИЗО открывает выставку «Актуальная Россия: среда обитания» шестидесяти современных русских художников, работающих в техниках актуального искусства. Выставка проходит в Музее современной истории России, который позиционируется как новая площадка на карте актуального искусства столицы. Открытие посетил В.Р. Мединский, отметив несправедливость замечания о том, что Министерство культуры РФ «не любит современное искусство» [23]. Выставка представляет кураторский взгляд на развитие современного российского искусства, по всей видимости, каким его понимает и хочет видеть государство.

Необходимость наращивать позиции «мягкой силы» как в постсоветском пространстве, так и в остальном мире [24] и формировать сплоченность внутри страны не лишены под собой разумных оснований. В контексте экономики знаний, творческих индустрий, креативных инвестиций в человека культура является залогом общественного процветания. Единая государственная стратегия способна задействовать большие ресурсы для ее развития. Коллизия возникает между патерналистским подходом к культуре, влекущем за собой попытки государственного регулирования сферы культуры и искусства, и необходимостью конкурентоспособ- ного существования отечественной культуры в глобальном мире. Современное искусство представляется одной из наиболее проблемных в данном смысле отраслей. Но именно развитие его инфраструктуры необходимо для формирования инновационной экономики, установления связей с мировыми культурными институциями и формирования будущего национального наследия. Вмешательство государства, присвоение чуждых ему компетенций может оказаться неэффективным в социокультурных условиях современного мира. В то время как «традиционная для России система ценностей» может вступать в противоречие со свободой творчества, гарантированной Конституцией РФ.

Китайская Народная Республика, начиная с 1980-х гг., модернизует свою культурную сферу, сделав ее движущим фактором модернизации и распространения влияния Китая в мире. Одинаково важным является и традиционное искусство, его поддержка и сохранение, и создание условий для появления нового, актуального искусства. В России искусство долгие годы развивалось само по себе, и хотя была сформирована инфраструктура арт-рынка, не было никаких преференций, налоговых льгот, закона о меценатстве, необходимых для его роста [25]. В Стратегии прописана «необходимость формирования условий для постепенного увеличения внебюджетных источников финансирования», которая может включать в себя «эффективную систему налоговых преференций», «маркированные налоги», «формы целевого капитала (эндаунмент-фонды)» [11]. Насколько эти меры будут перенесены с бумаги в реальную жизнь - судить пока сложно.

Анализ опыта КНР в отношении современного искусства позволяет отметить присущий китайской культуре прагматизм. Российская же стратегия развития культуры во многом движима амбициями духовного наставничества, приоритетами к сплоченности, народному единству, что, по всей видимости, будет определять контексты легитимного функционирования искусства в краткосрочной перспективе.

\section{Список источников}

1. Гройс Б. Топология современного искусства [Электронный ресурс] // Художественный журнал. 2006. № 61/62. URL: http://xz.gif.ru/numbers/61-62/ topologiya/ (дата обращения: 31.01.2017).

2. Move over Mao: Do China's artists serve a new master [Электронный ресурс] // CNN. Inside China. Chinese art today. URL: http://edition.cnn.com/ SPECIALS/1999/china.50/inside.china/art.overview/ (дата обращения: 01.12.2016).

3. Турушева Н.В. Политика Коммунистической партии Китая в области культуры в период реформ : автореф. дис. ... канд. ист. наук. Томск, 2013. 22 с.

4. Mad about museums. China is building thousands of new museums, but how will it fill them? [Электронный pe- 
cypc] // The Economist. URL: http://www.economist. com/news/special-report/21591710-china-buildingthousands-new-museums-how-will-it-fill-them-madabout-museums/ (дата обращения: 20.11.2016).

5. China's aggressive museum growth brings architectural wonders [Электронный ресурс] // CNN. URL: http:// edition.cnn.com/2014/04/29/world/asia/chinamuseums/ (дата обращения: 28.12.2016).

6. Арт 2 В \& В 2 Арт, или о том, что такое арт-рынок и как он работает : [монография] / И.Г. Хангельдиева, Н.Г. Чаган, Е.А. Карцева, Е.П. Катина. Москва : Русскій Міръ : Жизнь и мысль, 2016. 309 с.

7. Орлова М. Российский павильон в Венеции: чего это стоит [Электронный ресурс] // The Arts Newspaper Russia. 2013. № 14. URL: http://www.theartnewspaper. $\mathrm{ru} /$ posts/70/ (дата обращения: 20.10.2016).

8. Бюджет культуры в 2012 году составит 94 миллиарда рублей [Электронный ресурс] // Новости радио Культура. URL: http://old.cultradio.ru/doc. html?id=410618\&cid=44 (дата обращения: 04.12.2016).

9. Карцевва Е.A. Российский рынок современного искусства : качественный состав и внутренние противоречия // Вопросы культурологии. 2015. № 8 . C. $78-84$.

10. Лю Цзайции. «Мягкая сила» в стратегии развития Китая // Полис. Политические исследования. 2009. № 4. C. 149-155. URL: http://www.politstudies.ru/files/ File/2009/4/11.pdf (дата обращения: 04.12.2016).

11. Распоряжение Правительства Российской Федерации от 29 февраля 2016 г. № 326-р. Стратегия государственной культурной политики на период до 2030 года [Электронный ресурс] // Правительство Российской Федерации : официальный сайт. http:// government.ru/docs/all/105704/ (дата обращения: 01.12.2016).

12. Основы государственной культурной политики [Электронный ресурс] // Министерство культуры PФ : официальный сайт. URL: http://mkrf.ru/info/ foundations-state-cultural-policy/ (дата обращения: 01.12.2016).

13. Мороз О. Стратегии российской государственной культурной политики: опыт расследования [Электронный ресурс] // Журнальный клуб ИНТЕЛРОС. Интеллектуальная Россия. 2016. № 3. URL: http://www.intelros.ru/readroom/nz/ n3-2016/print:page,1,30615-strategii-rossiyskoygosudarstvennoy - kult urnoy - politiki - opyt rassledovaniya.html (дата обращения: 23.10.2016).

14. В Париже открылась выставка «Соц-Арт» [Электронный ресурс] // РИА Новости. URL: https://ria. $\mathrm{ru} /$ culture/20071021/84794954.html (дата обращения: 01.12.2016).
15. Министр культуры РФ встал на защиту современного искусства [Электронный ресурс] // РИА Новости. URL: https://ria.ru/culture/20131009/968755402.html (дата обращения: 01.12.2016).

16. Курдюкова Д. Размывай и подавляй [Электронный ресурс] // Независимая газета. 2016, 02 ноября. URL: http://www.ng.ru/culture/2016-11-02/2_6851_rosizo. html (дата обращения: 10.04.2017).

17. Павильон России на Биеннале в Венеции: участники поделились планами будущей экспозиции [Электронный ресурс] // Портал о культуре и искусстве Artandyou.ru. URL: http://artandyou.ru/category/ events/post/russian_pavilion_plans_revealed (дата обращения: 31.01.2016).

18. «Мы клевещем, доносим. И опять хотим в клетку»: речь Константина Райкина - о цензуре и борьбе государства за нравственность // Meduza. 2016, 24 октября. URL: https://meduza.io/feature/2016/10/24/ my-kleveschem-donosim-i-opyat-hotim-v-kletku (дата обращения: 10.04.2017).

19. Песков призвал не путать цензуру с госзаказом [Электронный ресурс] // Интерфакс. 2016, 25 октября. URL: http://www.interfax.ru/russia/533968 (дата обращения: 10.04.2017).

20. Ai Weiwei is named ArtReview's 'most powerful artist' [Электронный ресурс] // BBC NEWS. 2011, 13 октября. URL: http://www.bbc.com/news/entertainmentarts-15285939 (дата обращения: 23.10.2016).

21. В Минкульте прокомментировали выставку Яна Фабра в Эрмитаже [Электронный ресурс] // New Inform : Информационный портал. 2016, 12 ноября. URL: http://newinform.com/33648-v-minkulteprokommentirovali-vystavku-yana-fabra-v-ermitazhe (дата обращения: 10.04.2017).

22. Ерофеев А. Культура как противник. Актуальное российское искусство в условиях авторитарного режима [Электронный ресурс] // Андрей Ерофеев. Персональный сайт. URL: http://aerofeev.ru/index. php?option=com_content\&view=article\&id=337 (дата обращения: 31.01 .2017$)$.

23. Мединский открыл в Москве выставку современного искусства «Актуальная Россия» [Электронный ресурс] // ТАСС. Информационное агентство России. 2016, 17 ноября. URL: http://tass.ru/kultura/3792582 (дата обращения: 05.12.2016).

24. Карцева Е.А. Современное искусство как один из ресурсов формирования имиджа России за рубежом // Обсерватория культуры. 2016. Т. 13, № 3. С. 302-309.

25. Долганова Е.А. Арт-рынок в условиях современной России // Вопросы культурологии. 2011. № 2. С. $32-37$. 


\section{CONTEMPORARY ART IN THE CONTEXT OF STATE CULTURAL POLICY. THE RUSSIAN AND CHINESE EXPERIENCE}

\section{EKATERINA A. KARTSEVA}

International University in Moscow, 17, Leningradsky Av., Moscow, 125040, Russia

E-mail: katyakartseva@gmail.com

\begin{abstract}
In the past few years, the Russian cultural policy has been strongly affected by a number of state regulations and legal initiatives. There is an attempt to transform the old, narrowly departmentalized approach to the management in cultural sphere into a unified strategy of the state machinery. Culture has been elevated to the rank of national priorities. The state is willing to become one of its strategic investors and ideologists. The recently approved "Strategy of the State Cultural Policy for the Period till 2030" considers culture as a system of the traditional Russian values, conservation and support of which should be the guarantee of the national security and "civilization authenticity" of the country, facing the challenges of the outside world. The intensified governmental attention to the sphere of culture can be interpreted as a return of the paternalistic approach. In this regard, the contemporary art becomes one of the most problematic marginal fields that may run counter to the state cultural priorities, either in form or in content. It seems relevant to compare the Russian cultural policy in the contemporary art sphere with that in China, where culture, as a basis of the national security, is also raised to the level of state priorities.
\end{abstract}

Key words: contemporary art, cultural policy, art-market, Russia, China.

Citation: Kartseva E.A. Contemporary Art in the Context of State Cultural Policy. The Russian and Chinese Experience, Observatory of Culture, 2017, vol. 14, no. 2, pp. 157-166.

\section{References}

1. Groys B. Topologiya sovremennogo iskusstva [The Topology of Contemporary Art], Khudozhestvennyi zhurnal [Moscow Art Magazine], 2006, no. 61/62. Available at: http://xz.gif.ru/numbers/61-62/topologiya/ (accessed 31.01.2017).

2. Move over Mao: Do China's artists serve a new master? CNN. Inside China. Chinese Art Today. Available at: http://edition.cnn.com/SPECIALS/1999/china.50/ inside.china/art.overview/ (accessed 01.12.2016).

3. Turusheva N.V. Politika Kommunisticheskoi partii Kitaya $v$ oblasti kul'tury $v$ period reform [The Policy of the Communist Party of China in the Field of Culture in the Reform Period], Cand. hist. sci. diss. Abstr. Tomsk, 2013, $22 \mathrm{p}$.

4. Mad about museums. China is building thousands of new museums, but how will it fill them? The Economist. Available at: http://www.economist.com/news/ special-report/21591710-china-building-thousands-newmuseums-how-will-it-fill-them-mad-about-museums/ (accessed 20.11.2016).

5. China's aggressive museum growth brings architectural wonders, CNN. Available at: http://edition.cnn. com/2014/04/29/world/asia/china-museums/ (accessed 28.12.2016).

6. Khangeldieva I.G., Chagan N.G., Kartseva E.A., Katina E.P. Art 2 B \& B 2 Art, ili o tom, chto takoe art-rynok $i$ kak on rabotaet [Art 2 B \& B 2 Art, Or about What the Art Market Is and How It Works]. Moscow, Russkii Mir Publ., Zhizn' i mysl' Publ., 2016, 309 p.

7. Orlova M. Rossiiskii pavil'on v Venetsii: chego eto stoit [The Russian Pavilion in Venice: What Does It Take], The Art Newspaper Russia, 2013, no. 14. Available at: http://www.theartnewspaper.ru/posts/70/ (accessed 20.10.2016).

8. Byudzhet kul'tury v 2012 godu sostavit 94 milliarda rublei [The Budget of Culture in 2012 Will Amount to 94 Billion Rubles], Novosti radio Kul'tura [News of Radio Culture]. Available at: http://old.cultradio.ru/doc. html?id=410618\&cid=44 (accessed 04.12.2016).

9. Kartseva E.A. Rossiiskii rynok sovremennogo iskusstva: kachestvennyi sostav i vnutrennie protivorechiya [Russian Market of the Modern Art: Qualitative Structure and Internal Contradictions], Voprosy kul'turologii [Issues of Culturology], 2015. No. 8, pp. 78-84.

10. Lyu Tszaitsi. "Myagkaya sila" v strategii razvitiya Kitaya ["Soft Power" in China's Development Strategy], Polis. Politicheskie issledovaniya [Polis. Political Studies], 2009, no. 4, pp. 149-155. Available at:http://www.politstudies. ru/files/File/2009/4/11.pdf (accessed 04.12.2016).

11. Pravitel'stvo Rossiiskoi Federatsii. Rasporyazhenie ot 29 fevralya 2016 g. № 326-r. Strategiya gosudarstvennoi kul'turnoi politiki na period do 2030 goda [The Government of the Russian Federation. The Order Dated February 29, 2016, no. 326-r. The Strategy of the State Cultural Policy for the Period till 2030]. Available at: http:// government.ru/docs/all/105704 (accessed 01.12.2016).

12. Osnovy gosudarstvennoi kul'turnoi politiki [The Foundations of the State Cultural Policy], Ministerstvo kul'tury RF: ofitsial'nyi sait [The Ministry of Culture of the Russian Federation: the Official Website]. Available at: http:// mkrf.ru/info/foundations-state-cultural-policy/ (accessed 01.12.2016).

13. Moroz O. Strategii rossiiskoi gosudarstvennoi kul'turnoi politiki: opyt rassledovaniya [The Strategies of the Russian State Cultural Policy: the Investigation Experience], Zhurnal'nyi klub IN- 
TELROS. Intellektual'naya Rossiya [Journal Club INTELROS. The Intellectual Russia], 2016, no. 3. Available at: http://www.intelros.ru/readroom/nz/ n3-2016/print:page,1,30615-strategii-rossiyskoygosudarstvennoy-kulturnoy-politiki-opyt-rassledovaniya.html (accessed 23.10.2016).

14. V Parizhe otkrylas' vystavka "Sots-Art" [The Exhibition of "Sots Art" Opens in Paris], RIA Novosti [RIA News] Available at: https://ria.ru/culture/20071021/84794954.html (accessed 01.12.2016).

15. Ministr kul'tury RF vstal na zashchitu sovremennogo iskusstva [The Minister of Culture of the Russian Federation Stands Up For the Contemporary Art], RIA Novosti [RIA News]. Available at: https://ria. $\mathrm{ru} /$ culture/20131009/968755402.html (accessed 01.12.2016).

16. Kurdyukova D. Razmyvai i podavlyai [Blur and Suppress], Nezavisimaya gazeta [Independent Newspaper], 2016, 02 Nov. Available at: http://www.ng.ru/ culture/2016-11-02/2_6851_rosizo.html (accessed 10.04.2017).

17. Pavil'on Rossii na Biennale v Venetsii: uchastniki podelilis' planami budushchei ekspozitsii [The Russian Pavilion at the Venice Biennale: the Participants Share their Plans for the Future Exposure], Portal o kul'ture $i$ iskusstve Artandyou.ru [The Portal on Culture and Art Artandyou.ru]. Available at: http://artandyou.ru/ category/events/post/russian_pavilion_plans_revealed (accessed 31.01.2016).

18. "My kleveshchem, donosim. I opyat' khotim v kletku": rech' Konstantina Raikina - o tsenzure i bor'be gosudarstva za nravstvennost' ["We Slander, Denounce. And We Want Again in the Cage”: the Speech of Konstantin Raikin - about Censorship and the Government Struggling for Morality], Meduza, 2016, 24 October. Available at: https://meduza.io/feature/2016/10/24/mykleveschem-donosim-i-opyat-hotim-v-kletku (accessed 10.04.2017).
19. Peskov prizval ne putat' tsenzuru s goszakazom [Peskov Makes a Call not to Confuse Censorship with the State Order], Interfaks [Interfax], 2016, 25 Oct. Available at: http://www.interfax.ru/russia/533968 (accessed 10.04.2017).

20. Ai Weiwei is named ArtReview's "most powerful artist”, $B B C$ NEWS. 2011, 13 Oct. Available at: http://www. bbc.com/news/entertainment-arts-15285939 (accessed 23.10.2016).

21. V Minkul'te prokommentirovali vystavku Yana Fabra v Ermitazhe [The Ministry of Culture Comments on Jan Fabre's Exhibition at the Hermitage], New Inform. Informatsionnyi portal [New Inform. The Information Portal], 2016, 2 Nov. Available at: http://newinform.com/33648$\mathrm{v}$-minkulte-prokommentirovali-vystavku-yana-fabrav-ermitazhe (accessed 10.04.2017).

22. Erofeev A. Kul'tura kak protivnik. Aktual'noe rossiiskoe iskusstvo v usloviyakh avtoritarnogo rezhima [Culture as an Adversary. The Current Russian Art in the Conditions of Authoritarian Regime], Andrei Erofeev. Personal'nyi sait [Andrey Erofeev. The Personal Website]. Available at: http://aerofeev.ru/index.php?option=com content\&view=article\&id=337 (accessed 31.01.2017).

23. Medinskii otkryl v Moskve vystavku sovremennogo iskusstva "Aktual'naya Rossiya” [Medinsky Opens the Exhibition of Contemporary Art "Actual Russia” in Moscow], TASS. Informatsionnoe agentstvo Rossii [TASS. Russian News Agency], 2016, 17 Nov. Available at: http:// tass.ru/kultura/3792582 (accessed 05.12.2016).

24. Kartseva E.A. Sovremennoe iskusstvo kak odin iz resursov formirovaniya imidzha Rossii za rubezhom [Contemporary Art as a Source of Formation of the Image of Russia Abroad], Observatoriya kul'tury [Observatory of Culture], 2016, vol. 13, no. 3, pp. 302-309.

25. Dolganova E.A. Art-rynok v usloviyakh sovremennoi Rossii [Art Market in the Modern Russian Environment], Voprosy kul'turologii [Issues of Culturology], 2011, no. 2, pp. 32-37.

\section{НОВИНКА}

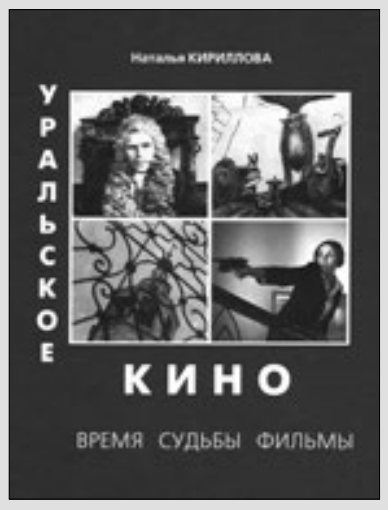

Кириллова НБ. Уральское кино: время, судьбы, фильмы : монография. Екатеринбург : Изд-во урал. ун-та, 2016. 432 c.

Новая книга Н.Б. Кирилловой, известного киноведа, доктора культурологии, заслуженного деятеля искусств РФ - итог многолетнего труда автора, занимающегося исследованием экранной культуры и сопричастного к процессам, происходящим в кинематографе во второй половине XX и начало XXI века.

В работе глубоко и обстоятельно показано, как в зеркале экрана отражается «запечатленное время» жизни нашей страны, Урала и всего мира за более чем вековую историю кинематографра.

В книге солидный справочный материал (документы, фотографии, библиография, избранная фильмография). 